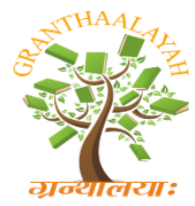

INTERNATIONAL JOURNAL OF RESEARCH GRANTHAALAYAH A knowledge Repository

Arts

\title{
FEMALE JEWELLERY OF THARU AND BUXA TRIBE OF UTTARAKHAND
}

\author{
Pooja Bhatt ${ }^{1}$, Anita Rani ${ }^{2}$, Manisha Gahlot ${ }^{3}$ \\ ${ }^{1}$ Senior Research Fellow, Department of Clothing and Textiles, Collage of Home Science \\ G.B.P.U.A \&T. Pantnagar, U.S.Nagar Uttarakhand, India \\ ${ }^{2}$ Associate Professor, Department of Clothing and Textiles, Collage of Home Science \\ G.B.P.U.A \&T. Pantnagar, U.S.Nagar Uttarakhand, India \\ ${ }^{3}$ Professor, Department of Clothing and Textiles, Collage of Home Science \\ G.B.P.U.A \&T. Pantnagar, U.S.Nagar Uttarakhand, India
}

\begin{abstract}
India is marked by its rich traditional heritage of tribal/folk arts and culture. Since the days of remote past, the diversified art \& cultural forms generated by the tribal and rural people of India have continued to evince their creative magnificence. Apart from their outstanding brilliance from the perspective of aesthetics, the tribal/folk art and culture forms have played an instrumental role in reinforcing national integrity, crystallizing social solidarity, fortifying communal harmony, intensifying value-system and promoting the elements of humanism among the people of the country. India has been endowed with a rich tribal culture, which despite modernisation has kept its unique traditions and values intact. Tribal Jewellery still bears a definite earthy charm. On the other hand, being different from the conventionally manufactured jewellery items, the rarity of ethnic jewellery is cherished by many. In the present study documentation of the tharu and buxa jewellery was done, and many similarities were observed.
\end{abstract}

Keywords: Tharu; Buxa; Tribe; Jewellery; Uttarakhand.

Cite This Article: Pooja Bhatt, Anita Rani, and Manisha Gahlot. (2018). "FEMALE JEWELLERY OF THARU AND BUXA TRIBE OF UTTARAKHAND." International Journal of Research - Granthaalayah, 6(1), 319-328. 10.29121/granthaalayah.v6.i1.2018.1623.

\section{Introduction}

Tharu is a dominant tribe of the state. The major concentration of the Tharu tribal population has been observed in the Tarai region of both states. There are many beliefs about their original habitats. There are several endogamous sub-groups of Tharu. Tharu of Uttarakhand are the Rana Tharu, claim themselves as Rajput by origin. According to them they are the ancestors of Maharana Pratap. Buxa tribe lives in Himalayan Tarai region of North India. Buxa are a formidable for constituting a majority in Ramnagar, Bajpur, and Kashipur blocks of the Nainital 
and Udham Singh Nagar districts. The Buxa tribe is a sub part of Tharu tribe but as a lowest clan of the Tharus. Tharu and Buxa both have same socio-cultural specialties (Tolia. NA).

Eclectic, earthen and funky are some of the adjectives that can be used to describe tribal jewellery, while arty, refined and evergreen can be used to describe ethnic jewellery. Even in the olden days, the tribes used every imaginable form of jewellery be it be the usual necklaces, bangles, and earrings or exotic items like ear cuffs, lip rings, and toe rings. Since most indigenous tribes were relatively poor or were frequently plundered by colonial powers, their selection of raw materials was humble and was limited to shells, claws, jaws of animals, ivory, wood, etc (Mohanty, 2006). Eclectic, earthen and funky are some of the adjectives that can be used to describe tribal jewellery, while arty, refined and evergreen can be used to describe ethnic jewellery. Even in the olden days, the tribes used every imaginable form of jewellery be it be the usual necklaces, bangles, and earrings or exotic items like ear cuffs, lip rings, and toe rings. Since most indigenous tribes were relatively poor or were frequently plundered by colonial powers, their selection of raw materials was humble and was limited to shells, claws, jaws of animals, ivory, wood, etc. Tribal jewellery communicates a lot about the wearer's status in the group, his wealth and possessions, spiritual beliefs and even functional habits. Thus, apart from depicting a customarily idealised appearance, the ornaments give a brief glimpse into the socio-cultural traditions of a particular group. (Cultural India, 2017).

\section{Results and Discussion}

Tharu female had ornaments for most of the body parts. Their jewellery was made in silver metal. It was found that they used maximum jewellery for their neck, which varied in length from the neck, weight and designs. Although entire community was poor but some people were comparatively well off. During the research it was found that people had sold their jewelleries to meet out their basic needs. So very few pictures were collected and that too from their jewellers. The details of the female jewellery of Tharu tribe are given in Table 1.

Table 1: Jewellery of females

\begin{tabular}{|c|l|l|l|}
\hline S. No. & Name of jewellery & Material used & Body parts where used \\
\hline a. & Ghunghat & Silver & Fore head \\
\hline b. & Nakfool & Silver & Nose \\
\hline c. & Karputiya & Silver & Ear \\
\hline d. & Bali & Silver & Ear \\
\hline e. & Pooj & Silver & Neck \\
\hline f. & Dulari & Silver & Neck \\
\hline g. & Hasuli & Silver & Neck \\
\hline h. & Khuthala & Silver & Neck \\
\hline i. & Sakri & Silver & Neck \\
\hline j. & Khaduva & Silver & Wrist \\
\hline k. & Bara & Silver & Wrist \\
\hline l. & Bank & Silver & Wrist \\
\hline m. & Parichan & Silver & Wrist \\
\hline n. & Paunchi & Silver & Wrist \\
\hline o. & Anghuthe & Silver & Fingers \\
\hline
\end{tabular}




\begin{tabular}{|c|l|l|l|}
\hline p. & Kaidhuni & Silver & Waist \\
\hline q. & Bankada & Silver & Feet \\
\hline r. & Lacche & Silver & Feet \\
\hline s. & Dagade & Silver & Toe fingers \\
\hline
\end{tabular}

The description of commonly used jewellery items owned by Tharu female is as follows:

1) Ghunghat - It was an ornament used at forehead during festive occasions, shown in Fig. 1(a). It was similar to belt or lace and measured half meter in length. This was very light in weight and flexible as well. It was stitched to the headgear, the argana, at the edge that falls on the forehead.

2) Nakfool - This was the ornament used by the Tharu female in one of the nostrils, usually the left. It could be of silver or gold. Its diameter was 0.75 inch.

3) Karputiya - It was a silver ornament worn on the ears. It was a small triangular pendant with long chain dangles ending in small flat pendants and was worn in pair worn at the sides of the head over temples. It was shown in Fig. 1(b).

4) Bali- It was the simple round ear ring made of silver. The diameter of the bali varied from 1 to 4 inch.

5) Pooj - It was a daily wear necklace possessed by Tharu women. It was made in silver, shown in Plate Fig. 3(c). It had two to three chains along with a leaf shape pendant at the middle of it.

6) Hansuli - This was a type of necklace, shown in Fig.1 (g). It was round collared necklace, worn tightly around the neck or resting on the collar bones. It was made of solid silver and had diameter up to $2.5 \mathrm{~cm}$ diameter hence quite heavy.

7) Kanthula- A necklace shown in Fig. 1 (e) is called kanthula. It was made of silver coins. It was interesting that sometimes Tharu men too wore coined necklaces. Kanthula consisted of 50 paisa coins.

8) Dulari- It was also similar to kanthula but instead of 50 paisa coins it had 25 paisa coins Fig.1 (d). Necklaces with coins were used to show the economic status of the tribal people.

9) Sakri - It was a neck ornament made by joining three chains together and joined by the knob shown in Fig.1 (e).

10) Khaduva- This was a thick silver bangle worn at the wrist, shown in Fig. 1(f).

11) Bara - This was meant to be worn on elbow, shown in Fig. 1(g).

12) Bank - It was the ornament for forearm. Fig. 1 (h) shows the bank.

13) All three were made of silver and differ very little in their design. Khaduva had pointed knob where as bara and bank had round and smooth edges.

14) Parichan- It is shown in Fig. 1 (i). It was made in silver metal. Parichan was like a bracelet with small bells all around it, which made pleasant sound. It had hinged and lock pattern.

15) Paunchi- It is shown in Fig. 1 (j). In paunchi diamond shaped beads of silver were stitched to the fabric. It was found that the fabric used on paunchi was black or red coloured shaneel (velvet). Threads were there to tie it on the wrist.

16) Anghuthe- It was ring, made in silver and could be worn at any finger.

17) Kaidhuni - It was a silver belt worn on the waist. It had 3 to 5 chains. It was worn occasionally over the ghaghara as shown in Fig.1 (k). 
18) Bankada - This was a silver ornament worn on the ankles. It was similar to khaduva of wrist in shape but lager in diameter as width of ankle is more than width of wrist. It is shown in Fig. 1 (1).

19) Lacche- These were silver ornament worn at the ankle. These were thin silver bangle with smooth surface. It had opening at one end finished with rounded knobs.

20) Daagde - It was similar to toe ring but in this three rings were joined together as shown in Fig. 1 (m).

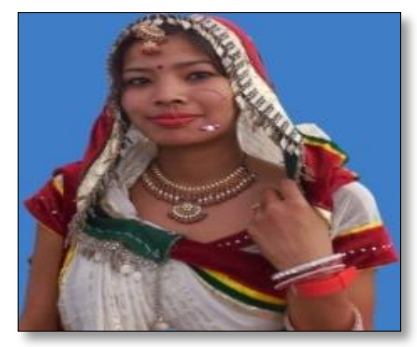

Figure 1(a): Ghunghat (forehead)

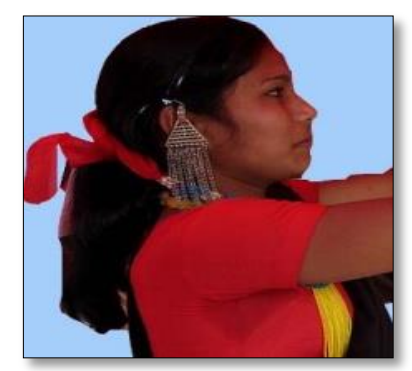

Figure 1(b): Karputiya (ear)

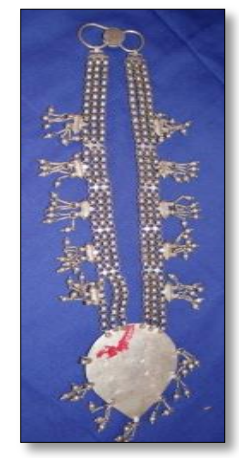

Figure 1(c): Pooj (neck)

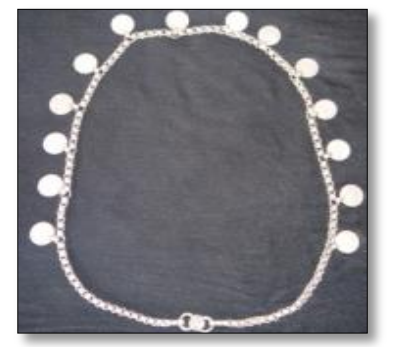

Figure 1(d): Dulari(neck) 


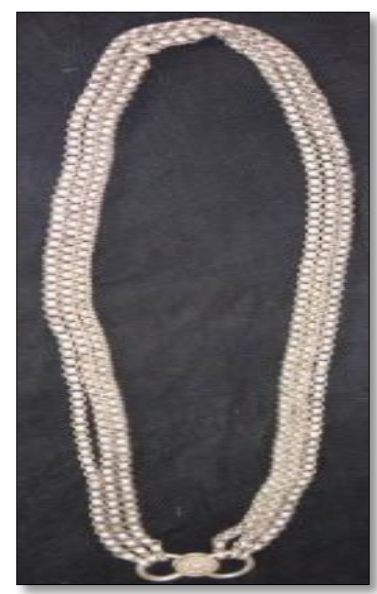

Figure 1(e): Sakai (neck)

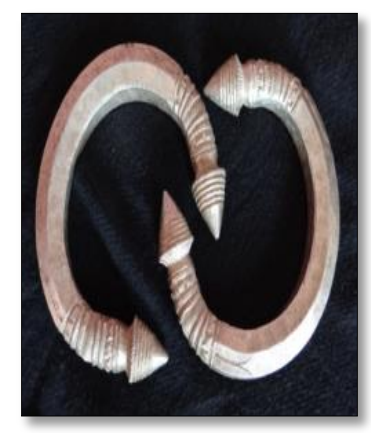

Figure 1(f): Khaduva (hand)

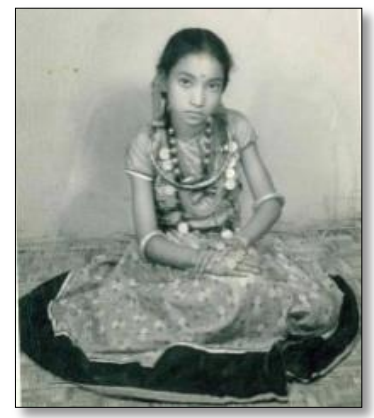

Figure 1(g): Bara and Hasuli (Hand and neck)

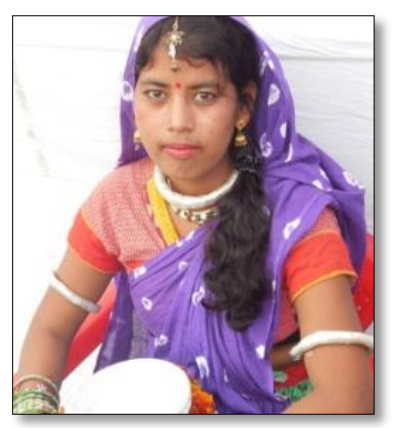

Figure 1(h): Bank 


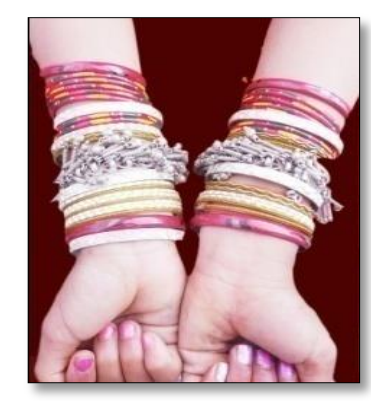

Figure 1(i): Parichan

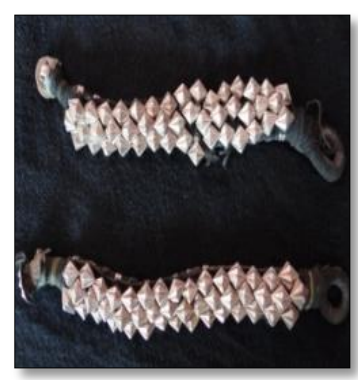

Figure 1(j): Paunchi

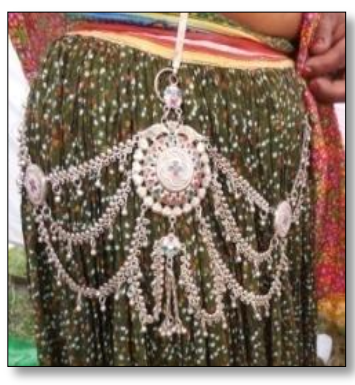

Figure 1(k): Kaidhuni Figure 1(1): Bankada

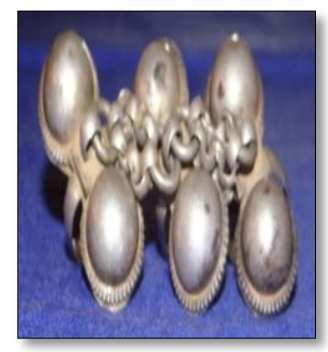

Figure 1(m): Dagade

Figure 1: Traditional jeweleries of Tharu tribe

Table 2: Jewellery of Buxa females

\begin{tabular}{|l|l|l|l|}
\hline S.No & Name of jewellery & Material used & Body parts where used \\
\hline a. & Nath & Gold & Nose \\
\hline b. & Fooli & Gold & Nose \\
\hline c. & Ghunghat & Silver & Fore head \\
\hline d. & Bundia & Gold or silver & Ear \\
\hline e. & Jhumka & Gold or silver & Ear \\
\hline f. & Bali & Gold or silver & Ear \\
\hline g. & Hasuli & Silver & Neck \\
\hline h. & Halem & Silver & Neck \\
\hline i. & Sankar & Silver & Neck \\
\hline j. & Khaila & Silver & upper arm \\
\hline k. & Bazuchak & Silver & upper arm \\
\hline l. & Kharwa & Silver & Wrist \\
\hline m. & Panhuchi & Silver & Wrist \\
\hline n. & Paribhand & Silver & Wrist \\
\hline o. & Hath phool/ mehndi & Silver & Hand \\
\hline p. & Challa & Silver & Thumb \\
\hline q. & Kardhani & Silver & Waist \\
\hline r. & Jhajan & Silver & Feet \\
\hline & & & \\
\hline
\end{tabular}

It can be envisaged from the Table 2 that Buxa females had jewellery for most of their body part. Most of the jewellery possessed by the Buxa female was made of silver metal. Jewellery of Buxa 
female had great similarity with the jewellery of Tharu females. This also exhibited that relationship existed between them.

1) Nath- It was a large ring worn in the left nostril. Nath was worn by the newly married lady. It was a circular ring made in gold metal.

2) Fooli- It was also a nose ornament. Fooli was a stone or gem studded nose pin of silver. It was worn by small girls and married females.

3) Ghunghat- It was a silver ornament, worn at fore head. It was stitched up with the uniya. It was similar to the Tharu female's ghughat in size and structure.

4) Bundiya-It was a stud made in silver. It was worn in the ear lobe by Buxa female.

5) Jhumka - It was a ear ornament made in silver metal. It had a stud, and with this a pendent or dialoguer was attached.

6) Bali- It was a small circular ring worn in the ears. It had smooth finish.

All these three ornaments could be worn all together one after another in the ear. Sometimes only one or two out of these three were worn by the female.

7) Hansuli- A type of silver necklace which was a rigid metal torque (a one-piece necklace that looks like a "C" with an opening at the back). This traditionally had geometric pattern engraved in it. It can be slender and lightweight or thick and very heavy in weight.

8) Halem - It was a special neck ornament of Buxa female. It is shown in Fig. 2 (a). This was brought by groom's family at the time of marriage. It had a locket at the centre this which was called as chauki. One rupee coins were also used in halem mala. Chauki and coins were tied together with bright coloured cotton thread.

9) Sankar - It was a long flattened silver chain for neck, shown in Fig. 2 (b). Three chains were joined together to form sankar.

10) Khaila - It was a sliver ornament worn on the fore arm. It was always worn in groups of three, shown in Fig. 2 (c). It is clear from the picture that it was round in shape and had smooth round knobs at the edges.

11) Bazuchak - It was a silver bangle to be worn on just above the elbow. It was thin as compared to khaila. Knobs were not found at the edges of the bazuchak. It is shown Fig. 2 (d).

12) Kharua - It was a silver bangle which was worn in pair. It is shown in Fig. 2 (e). It was wider and thinner than the other hand ornaments.

13) Pahunchi - It was a wrist ornament made in silver metal.

14) Paribhand - It was a silver ornament worn on the wrist. Small bells were hooked to it in all over its circumference. It is shown in Fig. 2 (f).

15) Panhuchi and paribhand were flexible bracelets. Both were similar to the panhuchi and paribhand of Tharu.

16) Hath phool - It was a silver ornament which covered the whole hand of the wearer from the back side. It consisted of five rings for fingers and a bangle for the wrist as shown in Fig. 2 (g). Five rings were joined with the bangle with the help of five chains and a floral design was also observed at the centre of it. 
17) Buxa people had many silver ornaments to be worn in their hand. All above stated hand ornament were worn in a fixed order which is as follows: Khaila, bazuchak, kharua, Panhuchi, paribhand and hath phool.

18) Challa - Ring called as challa is shown in Fig. 2 (h). It was worn in the thumb of hand as well as the thumb of feet. Only married women could wear this on the thumb of feet, as it was used to symbolize the marital status.

19) Kaidhuni- It was like a belt of silver metal worn at waist. It was shown in Fig. 2 (i). It was worn occasionally specially in marriage ceremony or any other festive occasions.

20) Jhajhan- It was an ornament meant for ankles. It was made in silver metal. These were hollow inside but small bells or sometimes stones were used inside them when the lady walks it made pleasant sound.

Among the all above stated ornaments Bundiya, kharuva and challa were worn in routine where as panhuchi, paribhand and kardhani were worn occasionally.

Men wore very few ornaments. Commonly ring or challa in fingers and kundal in the ears were used. Both were made form silver metal. This jewellery was only owned by the people with comparatively economically stable status.

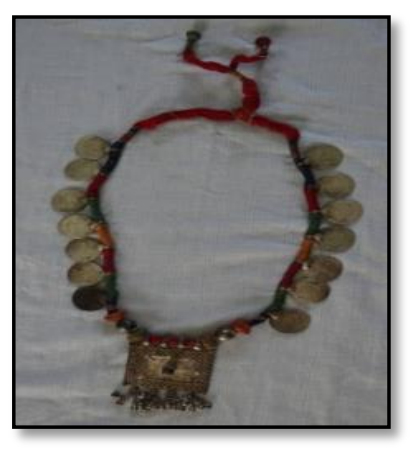

Figure 2(a) Halem (neck)

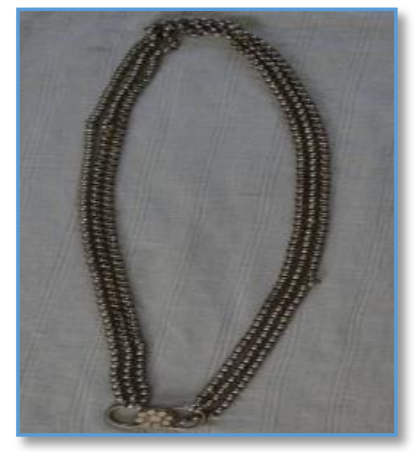

Figure 2 (b) Sankar (neck)

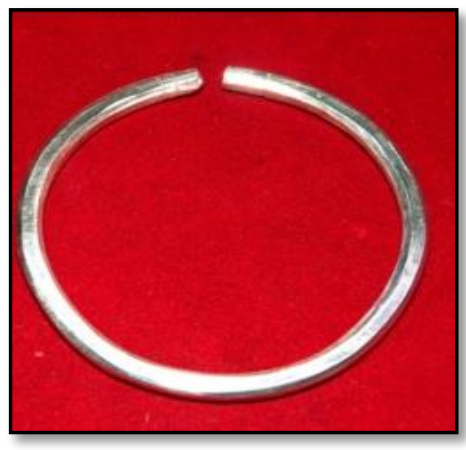

Figure 2(d) Kharua (wrist)

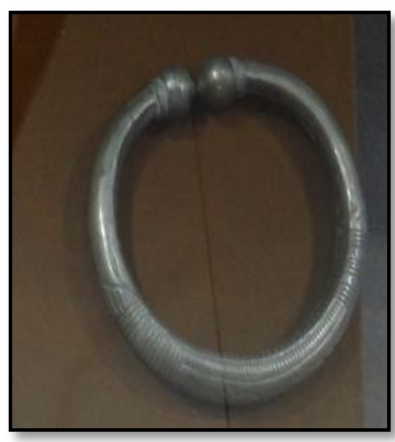

Figure 2(c) Khaila (wrist) 


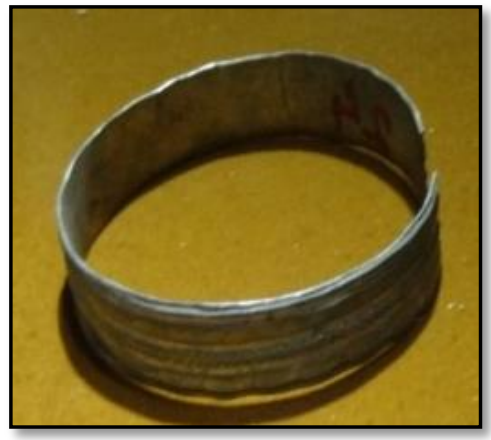

Figure 2(e) Bazuchak (wrist)

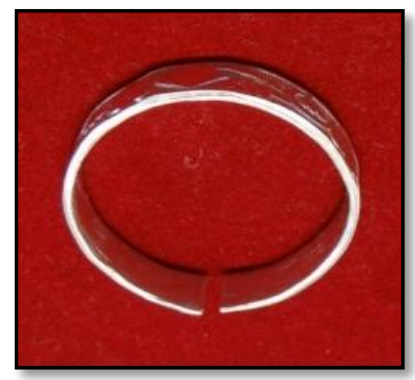

Figure 2(h) Challa (fingers)

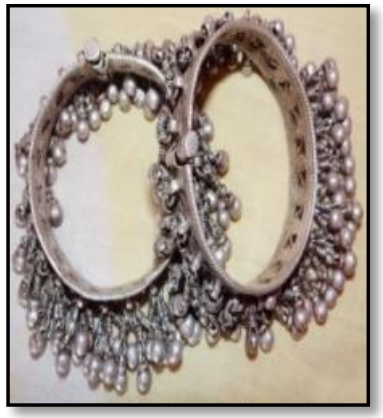

Figure 2(f) Paribhand (wrist) (hand)

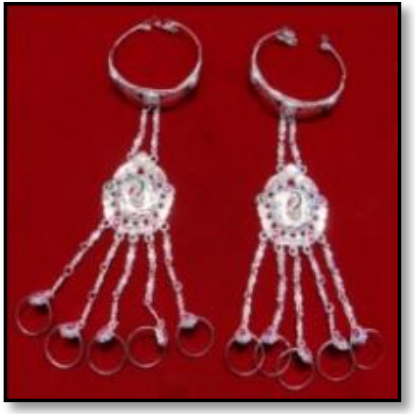

Figure 2(g) Hath phool

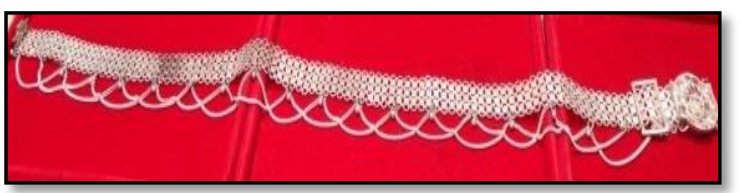

Figure 2(i) Kardhani (waist)

\section{Conclusion}

Females of Tharu tribe appeared to be fond of jewellery. They had ornaments for most of the body parts. Their jewellery was made in silver metal. It was found that they used maximum jewellery for the neck, which varied in length from the neck, weight and designs.

Buxa females loved to decorate them and were very fond of ornaments. Even small girls wear a few ornaments. Most of the jewellery possessed by the Buxa females was made of silver metal. Jewellery of Buxa females had great similarity with the jewellery of Tharu females, which depicts relationship that existed between them.

Both tribes used almost similar kind of jewellery made in silver metal. There were many items of jewellery items used by both the tribes which were worn on different body parts like forehead, ear, nose, neck, arm, wrist, ankle, toes and fingers. It was found that Tharu and Buxa both had similar socio-cultural specialties which had influence on their costumes too.

\section{Acknowledgement}

It gives me immense pleasure to avail the opportunity to show my deepest gratitude and reverence to all the faculty members and friends, Department of Clothing and Textiles, College of Home Science, G. B. P.U.A\& T, Pantnagar for their keen interest, continuous encouragement, intellectual guidance, constructive criticism and indispensable support. I would also thankful to The Heritage Museum, Anthropological Survey of India, Johar Milan Kendra, Rung Milan Kendra, Jaunsar-Bhawar Karmchari Mandal Sameeti for their immense support and cooperation during the research. 


\section{References}

[1] Indian Tribal and Ethnic Jewellery 2017 culturaral india. Retrieved from http://www.culturalindia.net/jewellery/types/tribal-jewellery.html on August 2017.

[2] Mohanty, P.K. (2006), "Encyclopedia of Scheduled Tribes in India", Vol.-2, Isha Books, New Delhi, P.240.

[3] Tolia R. S., NA. Great Tribal Diversity of Uttarakhand . Retrieved from http://uic.gov.in/Without\%20Fear\%20or\%20Favor/Great\%20Tribal\%20Diversity\%20of \%20Uttarakhand.pdf on May 2016.

*Corresponding author.

E-mail address: pooja.14sep@ gmail.com 